\title{
Associations of the MTHFR rs1801133 polymorphism with gastric cancer risk in the Chinese Han population
}

\author{
ZHIQIANG HAN $^{1 *}$, HUAMING SHENG ${ }^{2,3 *}$, QIUZHI GAO ${ }^{4}$, YU FAN $^{5}$ and XIANG XIE ${ }^{6}$ \\ ${ }^{1}$ Department of Osteology, Affiliated Hospital of Jiangsu University, Zhenjiang, Jiangsu 212000; ${ }^{2}$ Department of Oncology, \\ Jiangyin Hospital, Wuxi, Jiangsu 214400; ${ }^{3}$ School of Medicine, Southeast University, Nanjing, Jiangsu 210000; \\ ${ }^{4}$ School of Medicine, Jiangsu University, Zhenjiang, Jiangsu 212013; ${ }^{5}$ Cancer Institute, \\ Affiliated People's Hospital of Jiangsu University, Zhenjiang, Jiangsu 212002; \\ ${ }^{6}$ School of International Relations \& Public Affairs, Fudan University, \\ Shanghai 200000, P.R. China
}

Received February 22, 2020; Accepted October 23, 2020

DOI: $10.3892 /$ br.2020.1390

\begin{abstract}
In recent years, increasing evidence has implicated the importance of mutations in the MTHFR gene in the risk of gastric cancer risk. A single nucleotide polymorphism (SNP) in the MTHFR gene (rs1801133) may serve a critical role in gastric cancer. A hospital-based case-controlled study was performed to assess the risk of the rs1801133 polymorphism on gastric cancer. A total of 307 patients with gastric cancer and 560 patients in the control group were recruited. Genomic DNA was extracted from peripheral blood and genotyped for rs1801133 using the ligase detection reaction. The relationship between rs1801133 and gastric cancer risk was evaluated by unconditional logistical regression analysis. The rs1801133-TT genotype was associated with a borderline significantly decreased risk of gastric cancer [(TT vs. CC, adjusted odds ratio $(\mathrm{OR})=0.54,95 \%$ confidence intervals $(\mathrm{CI})=0.35-0.83 ; \mathrm{P}=0.006$; $\mathrm{CT}$ vs. $\mathrm{CC}$, adjusted $\mathrm{OR}=0.59,95 \% \mathrm{CI}=0.44-0.79, \mathrm{P}<0.001$; and TT/CT vs. CC, adjusted $\mathrm{OR}=0.61,95 \% \mathrm{CI}=0.44-0.83$, $\mathrm{P}=0.001$ ), and further analysis showed the relationship was evident amongst older patients and patients who never drank alcohol. The $\mathrm{C}>\mathrm{T}$ mutation at rs1801133 of the MTHFR gene was associated with a decreased risk of gastric cancer in older individuals and those who never drink.
\end{abstract}

\section{Introduction}

Gastric cancer is one of the most common types of cancer. Worldwide, gastric cancer has the fourth highest morbidity

Correspondence to: Dr Zhiqiang Han, Department of Osteology, Affiliated Hospital of Jiangsu University, 438 Jiefang Road, Zhenjiang, Jiangsu 212000, P.R. China

E-mail: zjhzq0812@sina.com

${ }^{*}$ Contributed equally

Key words: gastric cancer, MTHFR rs1801133, polymorphism, risk and the second highest mortality rate (1). However, the incidence and mortality of different types of gastric cancer vary; for example, there is a decrease in the incidence of non-cardia gastric cancer, concurrent with an increase in the morbidity and mortality rate of gastric cardia adenocarcinoma (2-5).

According to the statistics of Global Cancer in 2012, $\sim 952,000$ cases of stomach cancer were diagnosed, and there were $>700,000$ deaths, almost half of which came from China. Additionally, there were 405,000 new cases and 325,000 deaths in China (6). Developing countries have a higher proportion of gastric cancer cases, accounting for $70 \%$ of the worldwide total. Among these cases, East Asia accounts for $~ 50 \%$ of cases, and China is the worst affected, accounting for $45 \%$ of all gastric cancer-related deaths. Additionally, $42.6 \%$ of the incidence is attributed to China $(7,8)$. Several studies have shown the importance of various environmental factors on the risk of gastric cancer (9). In addition to environmental factors, the risk of gastric cancer is also influenced by internal factors, for example, age, genetic factors, lifestyle and sex. In particular, genetic factors may impact gastric cancer.

5,10 -methylene 4 hydrogen folate is a methylene 4 hydrogen folic acid reductase Methylenetetrahydrofolate reductase (MTHFR) catalyst, converts irreversibly into 5-methyl folate four hydrogen, which directs the distribution of folic acid derivatives to homocysteine remethylation and DNA methylation, or to biosynthesis of DNA and RNA, at a key metabolic branching point (10). Chromosome 1p36.3 contains 11 exons that encode MTHFR. More importantly, 5-MTHF is the only single carbon donor that produces homocysteine remethylation in the methionine cycle (11). The MTHFR gene contains > 20 SNPs, some of which are non-synonymous and some of which are associated with cancer risk. In particular, genetic polymorphisms in the MTHFR gene are associated with colorectal cancer risk $(12,13)$. A previous study found that rs4846048 increased the risk of colorectal cancer through its association with miR-522, and further regulated the survival and apoptosis of HeLa cells (14). Additionally, rs1801131 is associated with an increased risk of gastrointestinal toxicity (15), and the rs1801131-CC genotype is associated with sporadic breast cancer (16). The most frequently studied 
SNP is rs1801133, which is less common in gastric cancer; however, its role and prevalence in breast cancer and ovarian cancer have been studied (16-18).

It was found that rs 1801133 was associated with the risk of colorectal cancer $(19,20)$, ovarian cancer (17), gastric cancer (21) and liver cancer (22). To further verify whether rs1801133 is associated with the risk of gastric cancer, a case-controlled study was performed using individuals recruited from Zhenjiang (Jiangsu, China). The aim of the present study was to explore the relationship between rs1801133, environmental factors and the risk of gastric cancer.

\section{Materials and methods}

Ethics statement. The present hospital-based case-controlled study protocol was approved by the Ethics Committee for Human Subject study of Jiangsu University (Zhenjiang, China), and the study conformed to the guidelines of the Helsinki Declaration (23) on Ethical Behavior in Human Research.

Study population. All subjects in the present study, including the cases and controls, were of Chinese Han origin. A total of 307 patients with gastric cancer from the Affiliated People's Hospital of Jiangsu University and the Affiliated Hospital of Jiangsu University were collected between October 2014 and June 2016. Each patient was diagnosed with gastric cancer pathologically. The exclusion criteria were: Pre-existing cancer; the patient had undergone radiation or received chemotherapy; evidence of metastasis; or had an autoimmune disease. A total of 560 individuals with no cancer were recruited from the above two hospitals at the same time. Each of these individuals were interviewed to gather demographic data (such as age) and related risk factors (involving tobacco smoking and alcohol drinking). Participants who smoked at least 1 cigarette a day for 1 year were defined as 'smokers'. Individuals who had more than 3 drinks a week for 6 months were considered 'alcohol drinkers'. The median age was 63 years (age range, 40-90) in the case group and 62 years (age range, 40-88) in the control group. There were 223 males and 84 females amongst the case group, and 373 males and 187 females in the control group.

Genotyping. From each individual, 3-5 $\mathrm{ml}$ venous blood was collected. The sample was stored in a test tube lined with EDTA at $4^{\circ} \mathrm{C}$. Genomic DNA was extracted from whole blood samples using a commercially available DNA blood mini-kit (Qiagen, Inc.). Genotyping quality was determined using a procedure that included success rates of $>95 \%$, repeated genotyping, internal positive control samples, and Hardy-Weinberg Equilibrium (HWE) tests (24). The MTHFR tag SNP rs1801133 was assessed according to the HapMap Project and Haploview version 4.2 (ihg.gsf.de/cgi-bin/hw/hwa1. $\mathrm{pl})$. The ligase detection reaction method was used to genotype rs1801133, for which Shanghai Biowing Applied Biotechnology Company provided technical support (25). For quality control, 104 samples $(12.00 \%)$ were randomly reanalyzed, and the accuracy rate was $100 \%$ (data not shown). To analyze the regulome DB score, regulomedb.org/ was used, and to analyze the minor allele frequency in Chinese individuals, snpinfo. niehs.nih.gov/snpinfo/snpfunc.htm was used.
Statistical analysis. A t-test was used to compare the age of the cases and controls. A $\chi^{2}$ test was used to detect differences in demographic variables, variations between smoking status, history of alcohol consumption, and frequency of the rs1801133 genotype between the cases and controls. A HWE test determined the expected frequency in controls using the standard $\chi^{2}$ test. Deviations from HWE in the control group were assessed using an internet-based HWE tool (ihg.gsf.de/cgi-bin/hw/hwa1.pl) (26).

To assess the relationship between the genetic polymorphism and risk of gastric cancer, the odds ratio (OR) and 95\% confidence intervals (CIs) were calculated using unconditional logistical regression analysis, and adjusted for age, sex, smoking status and drinking history. Furthermore, genetic polymorphisms were stratified by age, sex, smoking status and drinking history. All statistical analyses was performed using SPSS version 21.0 (IBM Corp.). The data are expressed as the mean \pm standard deviation. All P-values are bilateral and $\mathrm{P}<0.05$ was considered to indicate a statistically significant difference.

\section{Results}

Characteristics of the study population. As shown in Table I, there were 307 cases and 560 controls included in the present study. There was no statistical difference in age and sex between the cases and the control groups $(\mathrm{P}=0.218$ and 0.067 , respectively). The case group contained 185 smokers and 122 nonsmokers. Meanwhile, in the controls, 373 individuals were smokers and 187 were non-smokers. There was a statistically significant difference between the case and the control group $(\mathrm{P}<0.001)$. However, there was no statistically significant difference in alcohol consumption $(\mathrm{P}=0.223)$.

The genotyping call rate was $100 \%$. In Table II, the genotype distribution of $\mathrm{rs} 1801133 \mathrm{C}>\mathrm{T}(\mathrm{P}=0.112)$ is shown, which conforms with the HWE $(\mathrm{P}>0.05)$. The minor allele frequency (MAF) in the controls is similar to the Chinese MAF in the SNP rs1801133 database (27).

rs1801133 and gastric cancer risk. The frequency of alleles and genotypes, and the associated ORs (95\% CI) between cases and controls are shown in Table III. The observed frequency of the rs1801133-T allele in the control group was $43.9 \%$, which was similar to the HapMap frequency of the Han Chinese in Beijing (44.4\%). Compared with the control group (44.37\%), the frequency of the $\mathrm{T}$ allele was significantly reduced (35.83\%). The frequency of rs1801133 genotypes was $29.3 \%$ (CC), $52.7 \%$ (CT), and $18 \%$ (TT) in controls, and $41.4 \%$ (CC), $45.6 \%$ (CT) and 13\% (TT) in cases, respectively.

When the rs1801133-CC homozygous genotype was used as the reference group, the CT genotype was associated with risk of gastric cancer (CT vs. $\mathrm{CC}, \mathrm{OR}=0.61$, 95\% $\mathrm{CI}=0.45-0.83, \mathrm{P}=0.002)$. The TT genotype was significantly associated with a reduced risk of gastric cancer (TT vs. $\mathrm{CC}, \mathrm{OR}=0.51,95 \% \mathrm{CI}=0.33-0.79, \mathrm{P}=0.002)$. In the dominant model, rs1801133-TT compared with rs1801133-CC genotype $(\mathrm{CT} / \mathrm{TT}$ vs. $\mathrm{CC}, \mathrm{OR}=0.59,95 \% \mathrm{CI}=0.44-0.79, \mathrm{P}<0.001)$ was also associated with a reduced risk of gastric cancer risk. In the recessive model, the TT homozygous genotype was not related to the risk of gastric cancer $(\mathrm{CC} / \mathrm{CT}$ vs. $\mathrm{TT}, \mathrm{OR}=0.68$, 
Table I. Clinicopathological characteristics and risk factors of the patients with in gastric cancer and control group.

\begin{tabular}{|c|c|c|c|c|c|}
\hline \multirow[b]{2}{*}{ Variable } & \multicolumn{2}{|c|}{$\begin{array}{l}\text { Cases, } \\
n=307\end{array}$} & \multicolumn{2}{|c|}{$\begin{array}{c}\text { Controls, } \\
n=560\end{array}$} & \multirow[b]{2}{*}{ P-value } \\
\hline & $\mathrm{n}$ & $\%$ & $\mathrm{n}$ & $\%$ & \\
\hline Age, years & & & & & 0.218 \\
\hline$\geq 63$ & 162 & 52.8 & 271 & 48.4 & \\
\hline$<63$ & 145 & 47.2 & 289 & 51.6 & \\
\hline Sex & & & & & 0.067 \\
\hline Male & 223 & 72.6 & 373 & 66.6 & \\
\hline Female & 84 & 27.4 & 187 & 33.4 & \\
\hline Smoking status & & & & & $<0.001^{\mathrm{a}}$ \\
\hline Never & 185 & 60.3 & 402 & 71.8 & \\
\hline Smoker & 122 & 39.7 & 158 & 28.2 & \\
\hline Alcohol use & & & & & 0.223 \\
\hline Never & 222 & 72.3 & 426 & 76.1 & \\
\hline Drinker & 85 & 27.7 & 134 & 23.9 & \\
\hline
\end{tabular}

${ }^{\mathrm{a}} \mathrm{P}<0.05$

Table II. Primary information of the MTHFR rs1801133 C>T polymorphisms.

\begin{tabular}{ll}
\hline Item & \multicolumn{1}{c}{ Information } \\
\hline Genotyped SNPs & MTHFR rs1801133 C>T \\
Chromosome & 1 \\
Gene Official Symbol & MTHFR \\
Function & Missense \\
Chromosome position & a \\
Regulome DB Score $^{\mathrm{b}}$ & 11778965 \\
nsSNP & 4 \\
$\begin{array}{l}\text { MAF for Chinese in } \\
\text { database }\end{array}$ & Y \\
MAF in our controls, & 0.439 \\
n=560 & \\
P-value for HWE test & 0.444 \\
in our controls & \\
Genotyping method & 0.112 \\
Genotyping value & LDR \\
\hline
\end{tabular}

aased on Genome Build version 36.3. ${ }^{\mathrm{b}}$ Based on regulomedb.org/. 'Based on snpinfo.niehs.nih.gov/snpinfo/snpfunc.htm. MAF, minor allele frequency; HWE, Hardy-Weinberg equilibrium; LDR, ligation detection reaction; SNP, single nucleotide polymorphism; nsSNP, nonsynonymous single nucleotide polymorphism.

95\% CI=0.46-1.01, $\mathrm{P}=0.681)$ using the $\mathrm{rs} 1801133-\mathrm{CC} / \mathrm{CT}$ genotypes as the reference group (Table III).

After adjustment for age, sex, smoking and drinking status, the TT genotype was associated with a significantly reduced risk of gastric cancer (TT vs. $\mathrm{CC}$, adjusted $\mathrm{OR}=0.54$,
95\% $\mathrm{CI}=0.35-0.83, \mathrm{P}=0.006$; $\mathrm{CT}$ vs. $\mathrm{CC}$, adjusted $\mathrm{OR}=0.59$, 95\% $\mathrm{CI}=0.44-0.79, \mathrm{P}<0.001$; and TT/CT vs. $\mathrm{CC}$, adjusted $\mathrm{OR}=0.61,95 \% \mathrm{CI}=0.44-0.83, \mathrm{P}=0.001)$. Using the $\mathrm{rs} 1801133$ $\mathrm{CC} / \mathrm{CT}$ genotype as the reference group, the TT homozygous genotype was not associated with gastric cancer risk (CC/CT vs. TT, $\mathrm{OR}=0.71,95 \% \mathrm{CI}=0.48-1.07, \mathrm{P}=0.098)$.

In order to evaluate the effects of the rs1801133 genotype on the risk of gastric cancer based on sex, smoking, age and alcohol consumption, a hierarchical analysis was performed (Table IV). Compared with the $\mathrm{CC}$ genotype, gastric cancer risk in the CT (adjusted $\mathrm{OR}=0.546,95 \% \mathrm{CI}=0.377-0.791, \mathrm{P}=0.001$ ) and TT (adjusted $\mathrm{OR}=0.447,95 \% \mathrm{CI}=0.276-0.823, \mathrm{P}=0.008$ ) and $\mathrm{CT} / \mathrm{TT}$ (adjusted $\mathrm{OR}=0.525,95 \% \mathrm{CI}=0.369-0.748, \mathrm{P}<0.001$ ) genotype carriers was significantly decreased for male patients. Compared with the $\mathrm{CC}$ and $\mathrm{CT}$ genotypes, gastric cancer risk in the $\mathrm{CT}$ (adjusted $\mathrm{OR}=0.590,95 \% \mathrm{CI}=0.378-0.920, \mathrm{P}=0.020$ ), TT (adjusted $\mathrm{OR}=0.369,95 \% \mathrm{CI}=0.181-0.753, \mathrm{P}=0.006$ ), $\mathrm{CT} / \mathrm{TT}$ (adjusted $\mathrm{OR}=0.534,95 \% \mathrm{CI}=0.348-0.818, \mathrm{P}=0.004$ ), and $\mathrm{CT}+\mathrm{CC}$ vs. TT (adjusted $\mathrm{OR}=0.500,95 \% \mathrm{CI}=0.259-0.967$, $\mathrm{P}=0.040$ ) genotype carriers was significantly decreased in the younger patients. For older patients, compared with the $\mathrm{CC}$ genotype, the risk of gastric cancer was reduced in the $\mathrm{CT}$ (adjusted $\mathrm{OR}=0.601,95 \% \mathrm{CI}=0.386-0.935, \mathrm{P}=0.024)$ and $\mathrm{CT} / \mathrm{TT}$ (adjusted $\mathrm{OR}=0.618,95 \% \mathrm{CI}=0.408-0.936, \mathrm{P}=0.023$ ) genotype carriers. In addition to internal factors, the $\mathrm{CT}$ genotype may decrease the risk of gastric cancer (CT vs. CC, adjusted $\mathrm{OR}=0.411,95 \% \mathrm{CI}=0.236-0.717, \mathrm{P}=0.002$; and TT/CT vs. $\mathrm{CC}$, adjusted $\mathrm{OR}=0.421,95 \% \mathrm{CI}=0.247-0.718, \mathrm{P}=0.001$ ) for those patients who have smoked. Based on alcohol consumption, the CT and TT genotypes may reduce gastric cancer risk (TT/CT vs. CC, adjusted $\mathrm{OR}=0.673,95 \% \mathrm{CI}=0.471-0.962$, $\mathrm{P}=0.030)$ for individuals who drink. The CT and TT genotype may decrease the risk of gastric cancer (CC vs. CT, adjusted $\mathrm{OR}=0.427,95 \% \mathrm{CI}=0.226-0.809, \mathrm{P}=0.002$, and $\mathrm{TT} / \mathrm{CT}$ vs. $\mathrm{CC}$, adjusted $\mathrm{OR}=0.437,95 \% \mathrm{CI}=0.237-0.804, \mathrm{P}=0.008$ ) for individuals who never drink.

\section{Discussion}

In the present hospital-based case-controlled study on gastric cancer, whether the functional SNP rs1801133 genotypes in the MTHFR gene affected the susceptibility of the Chinese Han population to gastric cancer was assessed in the present study. There was no evidence that rs1801133 TT, CT and TT/CT genotypes were associated with decreased risk of gastric cancer. The rs1801133 C>T polymorphism in the MTHFR gene was negatively associated with the risk of gastric cancer, as well as with age, smoking status and drinking history after correction.

Several studies have not been able to confirm a relationship between the MTHFR C677T genotype and gastric cancer susceptibility. The results of this study are consistent with those of Lin et al (28) and Chen et al (29), although the present study included more cases than the study by Lin et al (28). In the case group, more patients aged 55-63 years, male patients, and patients with a history of smoking and drinking were also enrolled in the present study. The study by Lin et al (28) recruited individuals predominantly from southern China, whereas the present study recruited individuals from eastern China primarily. Therefore, the present study is more relevant 
Table III. Logistical regression analyses of the associations between MTHFR rs1801133 C $>$ T polymorphisms and the risk of gastric cancer.

\begin{tabular}{|c|c|c|c|c|c|c|}
\hline $\begin{array}{l}\text { MTHFR rs } 1801133 \\
\text { C>T genotype }\end{array}$ & $\begin{array}{l}\text { Cases, } \\
\mathrm{n}(\%)\end{array}$ & $\begin{array}{l}\text { Controls, } \\
\mathrm{n}(\%)\end{array}$ & $\begin{array}{l}\text { Crude OR } \\
(95 \% \text { CI) }\end{array}$ & P-value & $\begin{array}{l}\text { Adjusted } \mathrm{OR}^{\mathrm{c}} \\
\quad(95 \% \mathrm{CI})\end{array}$ & $\begin{array}{l}\text { Adjusted } \\
\text { P-value }\end{array}$ \\
\hline $\mathrm{C}$ & $394(64.2)$ & $623(55.3)$ & & & & \\
\hline $\mathrm{T}$ & $220(35.3)$ & $497(44.4)$ & & & & \\
\hline $\mathrm{CC}$ & $127(41.4)$ & $164(29.3)$ & 1 & & & \\
\hline $\mathrm{TT}$ & $40(13)$ & $101(18)$ & $0.51(0.33-0.79)$ & 0.002 & $0.54(0.35-0.83)$ & $0.006^{\mathrm{a}}$ \\
\hline $\mathrm{CT}$ & $140(45.6)$ & $295(52.7)$ & $0.61(0.45-0.83)$ & 0.002 & $0.59(0.44-0.79)$ & $<0.001^{\mathrm{b}}$ \\
\hline $\mathrm{CT}+\mathrm{TT}$ & $180(58.6)$ & $396(70.7)$ & $0.59(0.44-0.79)$ & $<0.001$ & $0.61(0.44-0.83)$ & $0.001^{\mathrm{b}}$ \\
\hline $\mathrm{CC}+\mathrm{CT}$ & $167(54.4)$ & $265(47.3)$ & 1 & & & \\
\hline TT & $40(13)$ & $295(52.7)$ & $0.68(0.46-1.01)$ & 0.681 & $0.71(0.48-1.07)$ & 0.098 \\
\hline
\end{tabular}

${ }^{\mathrm{a}} \mathrm{P}<0.01,{ }^{\mathrm{b}} \mathrm{P}<0.001 .{ }^{\mathrm{c}}$ Adjusted for age, sex, smoking status and alcohol consumption. OR, odds ratio; CI, confidence interval.

for gastric cancer susceptibility in eastern China. However, as the results of the present study and Lin et al (28) were consistent, this highlights the potential generalizability of the results at least regarding the Chinese population.

Single nucleotide polymorphisms of the MTHFR gene are associated with the risk of gastric cancer (30). Chen et al (29) found that MTHFR 677TT was associated with a reduced risk of gastric cancer, which has been confirmed by another study (31). In other studies, several groups reported that carriers of the TT genotype had higher response rates or improved survival rates than the $\mathrm{CC}$ or $\mathrm{CT}$ genotypes in gastric cancer patients receiving 5-fluorouracil (5-FU) chemotherapy $(32,33)$. Of note, MTHFR polymorphisms have an impact on the efficacy of fluorouracil, as patients with different SNPs have been shown to have different reactivities $(34,35)$. The homozygous genotypes rs2274976-GG and rs1801131-AA were more common in reactive patients, whereas the rs2274976-A allele (GA and AA) and rs1801131-C allele (AC and CC) were more common in unresponsive patients (6). MTHFR polymorphisms may serve an important role in regulating the clinical toxicity and efficacy of 5-FU (36). The C677T SNP may predict toxicity in patients with metastatic colorectal cancer and fluorouracil chemotherapy in Costa Rica (37). However, patients with gastric cancer with CC or CT genotypes tended to have less chemotoxicity than those with the TT genotype. The C677T polymorphism predicted severe chemotoxicity in GC patients receiving 5-FU based chemotherapy, but could not predict efficacy (21). Chen et al (38) found a significant increase in gastric cancer risk in the Asian population. Zintzaras (39) performed study with 1,584 cases and 2,785 controls, and showed that the evidence for association between MTHFR polymorphisms and $\mathrm{GC}$ was predominantly present in East Asians and was not significant in Caucasians (39). To further clarify the relationship between the rs1801133 variant of the MTHFR gene and gastric cancer risk, the present case-controlled study using a large sample was performed. Through the analysis of alcohol consumption, sex, age and smoking status, it was shown that male, younger, former smokers and drinkers with the rs 1801133 $\mathrm{C}>\mathrm{T}$ variant had a reduced risk of gastric cancer.

$M T H F R$ polymorphisms are associated with the risk of neurological diseases, psoriasis, various types of cancer, infertility and vascular diseases (40). Folic acid levels are associated with the MTHFR C677T genotype binding and microRNA (miR)-21 expression. miR-21 is a noncoding small RNA that regulates gene expression and is often found in secreted microvesicles (41). Tumor-derived microbubbles induce skeletal muscle cell apoptosis, resulting in a decrease in skeletal muscle quality, which is a characteristic symptom of cancer cachexia (42).

The MTHFR gene produces methylene tetrahydrofolate reductase, a rate-limiting enzyme for folic acid metabolism and DNA methylation, and folic acid is essential to rescue a vulnerable state (43). It is an active $77 \mathrm{kDa}$ protein that catalyzes the transfiguration of 5, 10-methylenetetrahydrofolate to 5-methyltetrahydrofolate (44). There is evidence that MTHFR gene mutations lead to decreased thymidylate synthase (TS) activity in cancer cells, as a consequence of decreased levels of 5, 10-methylenetetrahydrofolate (45); the latter of which supplies the methyl for the methylation of dUMP to dTMP (46). TS is a critical and rate-limiting enzyme for maintaining an appropriate supply of DNA to ensure accurate DNA synthesis and repair (47). Thus, SNPs in the MTHFR gene may contribute to genetic susceptibility to cancer (48).

According to one report, the $\mathrm{C}>\mathrm{T}$ variant at nucleotide 677 (in exon 4 at the folate-binding site) leads to a valine substitution for alanine, which is functionally relevant, causing a reduction in the activity of MTHFR (19). Studies have shown that individuals who are heterozygous for the rs 1801133 polymorphism had $70 \%$ of the normal enzyme activity, while carriers of the homozygous polymorphism had only $30 \%$ of the normal enzyme activity (47), affecting folate metabolism (49). With regards to the relationship between MTHFR and folate, it has been shown that compound heterozygosity for the $677 \mathrm{~T}$ allele was associated with reduced plasma folic acid levels (50). Another study found that $\mathrm{rs} 1801133 \mathrm{C}>\mathrm{T}$ was related to low plasma folate content and significantly decreased MTHFR activity (51).

The present study has several limitations. Given that the case and control groups were recruited from the hospital, the study population may not represent the average Chinese Han population. Folate status may influence the relationship between the MTHFR SNP rs1801133 and gastric cancer 


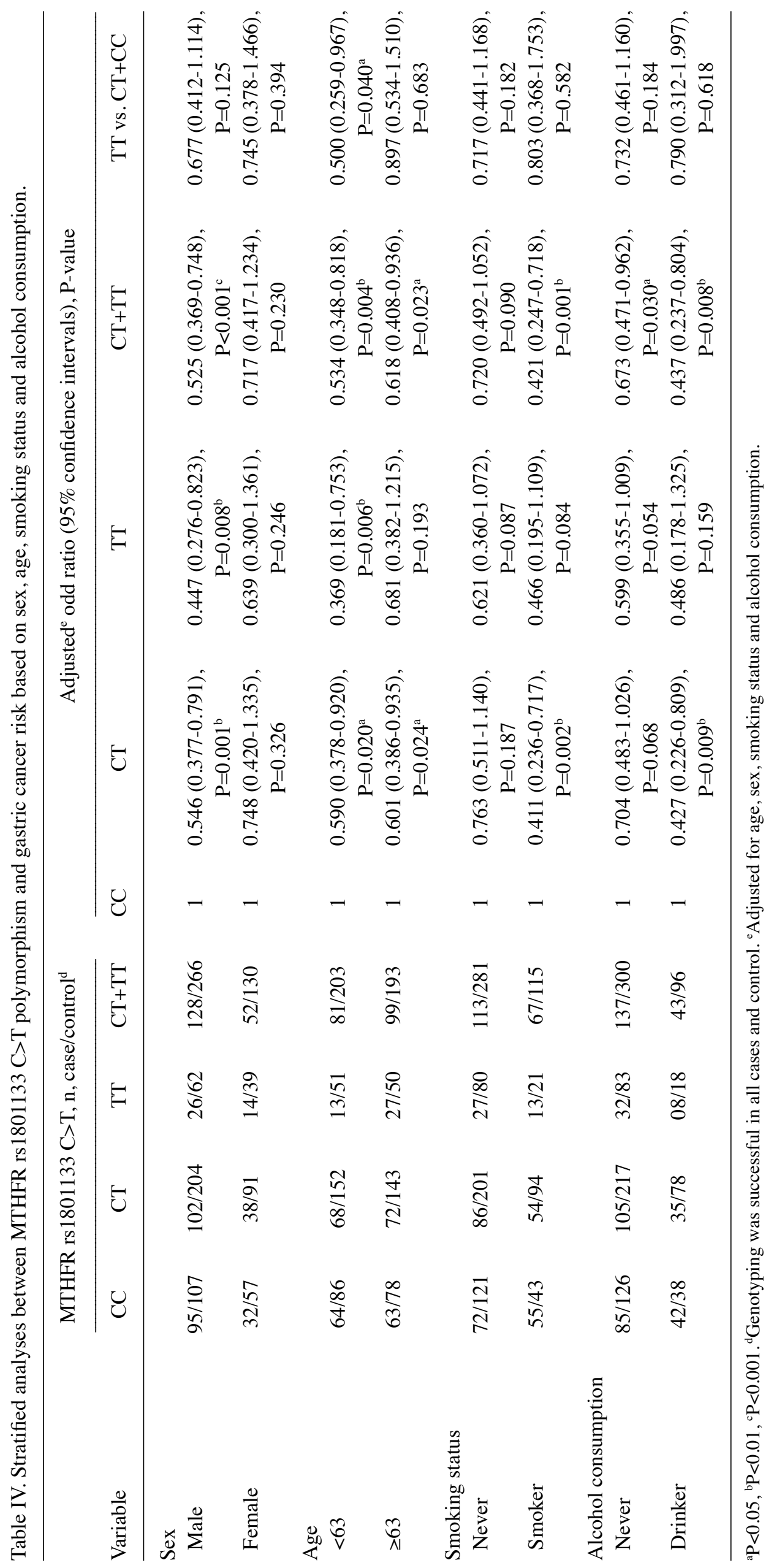


sensitivity. However, no data was available on the intake of folic acid in these subjects, for which a prospective study would be required. Finally, an even larger sample size is required to confirm the results. Further research is required to improve our understanding of the interactions between genes and the environment in the causation of gastric cancer.

In conclusion, the results of the present study showed that the functional MTHFR rs1801133 C>T polymorphism may contribute to the susceptibility of gastric cancer in Chinese Han individuals.

\section{Acknowledgements}

We would like to express our gratitude to Dr Wei Zhu for their valuable input. We would also like to thank Dr Mei Wang for assistance with revision of the manuscript.

\section{Funding}

This study was supported by funding from the Jiangsu Provincial Key Research and Development Special Fund (grant no. BE2015666) and the Jiangsu Innovative Team Leading Talent Fund (grant no. CXTDC2016006).

\section{Availability of data and materials}

The datasets used and/or analyzed during the present study are available from the corresponding author on reasonable request.

\section{Authors' contributions}

$\mathrm{ZH}$ and HS designed the study. QG acquired the data. QG and $\mathrm{ZH}$ wrote the manuscript. $\mathrm{ZH}$ and $\mathrm{HS}$ performed the experiments. YF and XX analyzed the results. HS and QG edited the manuscript. All authors read and approved the final manuscript.

\section{Ethics approval and consent to participate}

The experimental protocol used in the present study was approved by the Ethics Committee for Human Subject study of Jiangsu University (Zhenjiang, China). All patients provided written informed consent.

\section{Patient consent for publication}

Not applicable.

\section{Competing interests}

The authors declare that they have no competing interests.

\section{References}

1. Sun L, Wang Q, Chen B, Zhao Y, Shen B, Wang H, Xu J, Zhu M, Zhao X, Xu C, et al: Gastric cancer mesenchymal stem cells derived IL-8 induces PD-L1 expression in gastric cancer cells via STAT3/mTOR-c-Myc signal axis. Cell Death Dis 9: 928, 2018.

2. Potrc S, Ivanecz A, Krebs B, Marolt U, Iljevec B and Jagric T: Outcomes of the surgical treatment for adenocarcinoma of the cardia-single institution experience. Radiol Oncol 52: 65-74, 2018

3. Xin J, Wu Y, Wang X, Li S, Chu H, Wang M, Du M and Zhang Z: A transcriptomic study for identifying cardia- and non-cardia-specific gastric cancer prognostic factors using genetic algorithm-based methods. J Cell Mol Med 24: 9457-9465, 2020.
4. Nguyen TH, Mallepally N, Hammad T, Liu Y, Thrift AP, El-Serag HB and Tan MC: Prevalence of Helicobacter pylori positive non-cardia gastric adenocarcinoma is low and decreasing in a US population. Dig Dis Sci 65: 2403-2411, 2020.

5. Zhang X, Bai Z, Chen B, Feng J, Yan F, Jiang Z, Zhong Y, Wu J, Cheng L, Lu Z, et al: Polymorphism of methylenetetrahydrofolate reductase gene is associated with response to fluorouracil-based chemotherapy in Chinese patients with gastric cancer. Chin Med J (Engl) 127: 3562-3567, 2014.

6. Bray F, Ren JS, Masuyer E and Ferlay J: Global estimates of cancer prevalence for 27 sites in the adult population in 2008. Int J Cancer 132: 1133-1145, 2013.

7. Wang W, Sun Z, Deng JY, Qi XL, Feng XY, Fang C, Ma XH, Wang ZN, Liang H, Xu HM and Zhou ZW: A novel nomogram individually predicting disease-specific survival after D2 gastrectomy for advanced gastric cancer. Cancer Commun (Lond) 38: 23, 2018.

8. Torre LA, Bray F, Siegel RL, Ferlay J, Lortet-Tieulent J and Jemal A: Global cancer statistics, 2012. CA Cancer J Clin 65: 87-108, 2015.

9. Zhang XM, Zhong R, Liu L, Wang Y, Yuan JX, Wang P, Sun C, Zhang Z, Song WG and Miao XP: Smoking and COX-2 functional polymorphisms interact to increase the risk of gastric cardia adenocarcinoma in Chinese population. PLoS One 6: e21894, 2011.

10. Selhub J: Homocysteine metabolism. Ann Rev Nutri 19: 217-246, 1999.

11. Luo Z, Lu Z, Muhammad I, Chen Y, Chen Q, Zhang J and Song Y: Associations of the MTHFR rs1801133 polymorphism with coronary artery disease and lipid levels: A systematic review and updated meta-analysis. Lipids Health Dis 17: 191, 2018.

12. Jamshidi M, Mohammadi Pour S and Mahmoudian-Sani MR: Single nucleotide variants associated with colorectal cancer among Iranian patients: A narrative review. Pharmgenomics Pers Med 13: 167-180, 2020.

13. Ozen F, Sen M and Ozdemir O: Methylenetetrahydrofolate reductase gene germ-line C677T and A1298C SNPs are associated with colorectal cancer risk in the Turkish population. Asian Pac J Cancer Prev 15: 7731-7735, 2014.

14. Zhou X, Shan L, Na J, Li Y and Wang J: The SNP rs4846048 of MTHFR enhances the cervical cancer risk through association with miR-522: A preliminary report. Mol Genet Genomic Med 8: e1055, 2020.

15. De Marchi P, Melendez ME, Laus AC, Kuhlmann PA, de Carvalho AC, Arantes LMRB, Evangelista AF, Andrade ES, de Castro G Junior, Reis RM, et al: The role of single-nucleotide polymorphism (SNPs) in toxicity of induction chemotherapy based on cisplatin and paclitaxel in patients with advanced head and neck cancer. Oral Oncol 98: 48-52, 2019.

16. Hardi H, Melki R, Boughaleb Z, El Harroudi T, Aissaoui S and Boukhatem N: Significant association between ERCC2 and MTHR polymorphisms and breast cancer susceptibility in Moroccan population: Genotype and haplotype analysis in a case-control study. BMC Cancer 18: 292, 2018.

17. Xiong Y, Bian C, Lin X, Wang X, Xu K and Zhao X: Methylenetetrahydrofolate reductase gene polymorphisms in the risk of polycystic ovary syndrome and ovarian cancer. Biosci Rep 40: BSR20200995, 2020.

18. Floris M, Sanna D, Castiglia P, Putzu C, Sanna V, Pazzola A, De Miglio MR, Sanges F, Pira G, Azara A, et al: MTHFR, XRCC1 and OGG1 genetic polymorphisms in breast cancer: A case-control study in a population from North Sardinia. BMC Cancer 20: 234, 2020.

19. Le Marchand L, Wilkens LR, Kolonel LN and Henderson BE: The MTHFR C677T polymorphism and colorectal cancer: The multiethnic cohort study. Cancer Epidemiol Biomarkers Prev 14: 1198-1203, 2005

20. Slattery ML, Potter JD, Samowitz W, Schaffer D and Leppert M: Methylenetetrahydrofolate reductase, diet, and risk of colon cancer. Cancer Epidemiol Biomarkers Prev 8: 513-518, 1999.

21. Tang C, Yu S, Jiang H, Li W, Xu X, Cheng X, Peng K, Chen E, Cui Y and Liu T: A meta-analysis: Methylenetetrahydrofolate reductase C677T polymorphism in gastric cancer patients treated with 5 -Fu based chemotherapy predicts serious hematologic toxicity but not prognosis. J Cancer 9: 1057-1066, 2018.

22. Zhang S, Lin J, Jiang J, Chen Y, Tang W and Liu L: Association between methylenetetrahydrofolate reductase tagging polymorphisms and susceptibility of hepatocellular carcinoma: A case-control study. Biosci Rep 39: BSR20192517, 2019. 
23. World Medical Association (WMA): WMA Declaration of Helsinki - Ethical Principles for Medical Research Involving Human Subjects. WMA, Ferney-Voltaire, 2018. https://www. wma.net/policies-post/wma-declaration-of-helsinki-ethical-principles-for-medical-research-involving-human-subjects/. Accessed July 9, 2018.

24. Rohlfs RV and Weir BS: Distributions of Hardy-Weinberg equilibrium test statistics. Genetics 180: 1609-1616, 2008.

25. Hou G, Jin Y, Liu M, Wang C and Song G: UCP2-866G/A polymorphism is associated with prediabetes and type 2 diabetes. Arch Med Res 51: 556-563, 2020.

26. Sohn KJ, Croxford R, Yates Z, Lucock M and Kim YI: Effect of the methylenetetrahydrofolate reductase C677T polymorphism on chemosensitivity of colon and breast cancer cells to 5-fluorouracil and methotrexate. J Natl Cancer Inst 96: 134-144, 2004

27. Tang W, Zhang S, Qiu H, Wang L, Sun B, Yin J and Gu H: Genetic variations in MTHFR and esophageal squamous cell carcinoma susceptibility in Chinese Han population. Med Oncol 31: 915, 2014.

28. Lin J, Zeng RM, Li RN and Cao WH: Aberrant DNA methylation of the P16, MGMT, and hMLH1 genes in combination with the methylenetetrahydrofolate reductase C677T genetic polymorphism and folate intake in gastric cancer. Genet Mol Res 13: 2060-2068, 2014.

29. Chen J, Yuan L, Duan YQ, Jiang JQ, Zhang R, Huang ZJ and Xiao XR: Impact of methylenetetrahydrofolate reductase polymorphisms and folate intake on the risk of gastric cancer and their association with Helicobacter pylori infection and tumor site. Genet Mol Res 13: 9718-9726, 2014.

30. Li S, Ji M, He N and Lu Z: Application of microarray-based method for methylenetetrahydrofolate reductase (MTHFR) polymorphisms in the risk of gastric carcinoma in east China population. J Nanosci Nanotechnol 7: 3245-3249, 2007.

31. Galván-Portillo MV, Oñate-Ocaña LF, Pérez-Pérez GI, Chen J, Herrera-Goepfert R, Chihu-Amparan L, Flores-Luna L, Mohar-Betancourt A and López-Carrillo L: Dietary folate and vitamin B12 intake before diagnosis decreases gastric cancer mortality risk among susceptible MTHFR 677TT carriers. Nutrition 26: 201-208, 2010.

32. Lu JW, Gao CM, Wu JZ, Sun XF, Wang L and Feng JF: Relationship of methylenetetrahydrofolate reductase C677T polymorphism and chemosensitivity to 5-fluorouracil in gastric carcinoma. Ai Zheng 23: 958-962, 2004 (In Chinese).

33. Rozen R: Molecular genetics of methylenetetrahydrofolate reductase deficiency. J Inherit Metab Dis 19: 589-594, 1996.

34. Custodio A, Moreno-Rubio J, Aparicio J, Gallego-Plazas J, Yaya R, Maurel J, Rodríguez-Salas N, Burgos E, Ramos D, Calatrava A, et al: Pharmacogenetic predictors of outcome in patients with stage II and III colon cancer treated with oxaliplatin and fluoropyrimidine-based adjuvant chemotherapy. Mol Cancer Ther 13: 2226-2237, 2014.

35. Cecchin E, Perrone G, Nobili S, Polesel J, De Mattia E, Zanusso C, Petreni P, Lonardi S, Pella N, D'Andrea M, et al: MTHFR-1298 A>C (rs1801131) is a predictor of survival in two cohorts of stage II/III colorectal cancer patients treated with adjuvant fluoropyrimidine chemotherapy with or without oxaliplatin. Pharmacogenomics J 15: 219-225, 2015.
36. De Mattia E and Toffoli G: C677T and A1298C MTHFR polymorphisms, a challenge for antifolate and fluoropyrimidine-based therapy personalisation. Eur J Cancer 45: 1333-1351, 2009.

37. Ramos-Esquivel A, Chinchilla $\mathrm{R}$ and Valle M: Association of C677T and A1298C MTHFR polymorphisms and fluoropyrimidine-induced toxicity in mestizo patients with metastatic colorectal cancer. Anticancer Res 40: 4263-4270, 2020.

38. Chen L, Lu N, Zhang BH, Weng LI and Lu J: Association between the MTHFR C677T polymorphism and gastric cancer susceptibility: A meta-analysis of 5,757 cases and 8,501 controls. Oncol Lett 10: 1159-1165, 2015

39. Zintzaras E: Association of methylenetetrahydrofolate reductase (MTHFR) polymorphisms with genetic susceptibility to gastric cancer: A meta-analysis. J Hum Genet 51: 618-624, 2006.

40. Liew SC and Gupta ED: Methylenetetrahydrofolate reductase (MTHFR) C677T polymorphism: Epidemiology, metabolism and the associated diseases. Eur J Med Genet 58: 1-10, 2015.

41. Beckett EL, Martin C, Choi JH, King K, Niblett S, Boyd L, Duesing K, Yates Z, Veysey M and Lucock M: Folate status, folate-related genes and serum miR-21 expression: Implications for miR-21 as a biomarker. BBA Clin 4: 45-51, 2015.

42. He WA, Calore F, Londhe P, Canella A, Guttridge DC and Croce CM: Microvesicles containing miRNAs promote muscle cell death in cancer cachexia via TLR7. Proc Natl Acad Sci USA 111: 4525-4529, 2014.

43. Vidmar Golja M, Smid A, Karas Kuzelicki N, Trontelj J, Gersak K and Mlinaric-Rascan I: Folate insufficiency due to MTHFR deficiency is bypassed by 5-methyltetrahydrofolate. J Clin Med 9: 2020.

44. Kim YI: Methylenetetrahydrofolate reductase polymorphisms, folate, and cancer risk: A paradigm of gene-nutrient interactions in carcinogenesis. Nutr Rev 58: 205-209, 2000.

45. Tan W, Miao X, Wang L, Yu C, Xiong P, Liang G, Sun T, Zhou Y, Zhang X, Li H and Lin D: Significant increase in risk of gastroesophageal cancer is associated with interaction between promoter polymorphisms in thymidylate synthase and serum folate status. Carcinogenesis 26: 1430-1435, 2005.

46. Chai W, Zhang Z, Ni M, Geng P, Lian Z, Zhang G, Shi LL and Chen J: Genetic association between methylenetetrahydrofolate reductase gene polymorphism and risk of osteonecrosis of the femoral head. Biomed Res Int 2015: 196495, 2015.

47. Jain M, Pandey P, Tiwary NK and Jain S: MTHFR C677T polymorphism is associated with hyperlipidemia in women with polycystic ovary syndrome. J Hum Reprod Sci 5: 52-56, 2012.

48. Födinger M, Wagner OF, Hörl WH and Sunder-Plassmann G: Recent insights into the molecular genetics of the homocysteine metabolism. Kidney Int Suppl 78: S238-S242, 2001.

49. Kim YI: Role of the MTHFR polymorphisms in cancer risk modification and treatment. Future Oncol 5: 523-542, 2009.

50. Bezerra JF, Oliveira GH, Soares CD, Cardoso ML, Ururahy MA, Neto FP, Lima-Neto LG, Luchessi AD, Silbiger VN, Fajardo CM, et al: Genetic and non-genetic factors that increase the risk of non-syndromic cleft lip and/or palate development. Oral Dis 21: 393-399, 2015.

51. Ericson UC, Ivarsson MI, Sonestedt E, Gullberg B, Carlson J, Olsson $\mathrm{H}$ and Wirfält E: Increased breast cancer risk at high plasma folate concentrations among women with the MTHFR 677T allele. Am J Clin Nutr 90: 1380-1389, 2009. 